Jacinta J. Maas

Michael R. Pinsky

Bart F. Geerts

Rob B. de Wilde

Jos R. Jansen

\section{Erratum to: Estimation of mean systemic filling pressure in postoperative cardiac surgery patients with three methods}

Published online: 6 November 2012

(C) Springer-Verlag Berlin Heidelberg and ESICM 2012

The online version of the original article can be found under doi:10.1007/s00134-012-2586-0.

J. J. Maas $(\bowtie)$. R. B. de Wilde · J. R. Jansen

Department of Intensive Care Medicine, Leiden University Medical Center, PO Box 9600, 2300 RC Leiden, The Netherlands

e-mail: j.j.maas@lumc.nl

Tel.: +31-71-5265018

Fax: +31-71-5266966

M. R. Pinsky

Department of Critical Care Medicine, University of Pittsburgh, Pittsburgh, PA, USA

B. F. Geerts

Department of Anesthesiology, Leiden University Medical Center, Leiden, The Netherlands

\section{Erratum to: Intensive Care Med (2012) 38:1452-1460} DOI 10.1007/s00134-012-2586-0

The formula for computation of factor $c$, used in calculating mean systemic pressure, unfortunately contained an error $\left(0.9^{(\text {age }-15)}\right.$ instead of the correct $\left.0.99^{(\text {age }-15)}\right)$. The passage concerned is given here in full, with the formula corrected:

The Pmsa estimate [9] uses a mathematical model of the systemic circulation comprising compliant arterial and venous compartments and resistances to blood flow. The model parameters are adjusted to match those of the patient's current measured variables, such that Pmsa $=a \times \mathrm{Pcv}+b \times \mathrm{Pa}+c \times \mathrm{CO}$, where $a$ and $b$ are dimensionless constants $(a+b=1$, typically $a=0.96$, $b=0.04)$, and $c$ has the dimensions of resistance and is a function of the patient's height, weight and age:

$$
\begin{aligned}
c= & 0.038 \times(94.17+0.193 \times \text { age }) /\left(4.5 \times\left[0.99^{(\text {age }-15)}\right]\right. \\
& \left.\times 0.007184 \times\left[\text { height }^{0.725}\right] \times\left[\text { weight }^{0.425}\right]\right) .
\end{aligned}
$$

